\title{
FGF 23 and trabecular microarchitecture
}

\author{
S. Minisola ${ }^{1}$ (D) $\cdot$ L. Colangelo ${ }^{1} \cdot$ C. Cipriani ${ }^{1} \cdot$ J. Pepe $^{1}$
}

Received: 7 July 2019 / Accepted: 1 August 2019 / Published online: 12 August 2019

(C) International Osteoporosis Foundation and National Osteoporosis Foundation 2019

\section{Dear Editor,}

We were intrigued by the paper of Rupp and coworkers; they showed that fibroblast growth factor 23 (FGF23) levels are associated with impaired trabecular bone microarchitecture in patients with osteoporosis, also after adjusting for confounding variables [1].

However, looking at Fig. 2, it seems that the correlations reported are mainly driven by two subjects with very high levels of C-terminal FGF23. Indeed, the maximum value of FGF23 reported in Table 1 is $1105 \mathrm{kRU} / \mathrm{L}$, a level far above those found in normal subjects and also sometimes difficult to encounter in specific conditions characterized by hypersecretion of FGF23 such as tumor-induced osteomalacia [2]. Firstly, we wonder which could be the possible explanation underlying such high values in patients with osteoporosis and supposedly normal phosphate values. Secondly, it would be important to know if the correlations found persisted after excluding these clearly outlier subjects. Finally, we wonder if these correlations could have been improved by utilizing more recent assays detecting only the entire molecule $[2,3]$.

Regardless, we appreciate the point raised by the authors' findings suggesting a putative direct role of FGF23 on biomineralization and consequently on trabecular microstructure. Some preclinical data seem in fact to suggest that the $\mathrm{Npt}^{(--)}$ mice that exhibit increased urinary phosphate excretion do not develop a skeletal phenotype of comparable severity to Hyp mouse [4]. In particular, they showed delayed trabecular bone formation without huge non-mineralized bone matrix. A direct effect of FGF23 on bone mineralization process could therefore represent an adjunctive mechanism to those already largely acknowledged (i.e., low circulating phosphate and low calcium absorption owing to downregulation of 1 alpha 25hydroxyvitamin D) leading to impaired bone mineralization.

\section{Compliance with ethical standards}

Conflict of interest None.

\section{References}

1. Rupp T, Butscheidt S, Vettorazzi E, Oheim R, Barvencik F, Amling M, Rolvien T $(2019,2019)$ High FGF23 levels are associated with impaired trabecular bone microarchitecture in patients with osteoporosis. Osteoporos Int. https://doi.org/10. 1007/s00198-019-04996-7

2. Minisola S, Peacock M, Fukumoto S, Cipriani C, Pepe J, Tella SH, Collins MT (2017) Tumour-induced osteomalacia. Nat Rev Dis Primers 13(3):17044. https://doi.org/10.1038/nrdp.2017.44

3. Colangelo L, Cipriani C, Pepe J, Corsi A, Sonato C, Follacchio G, Cilli M, Gianni W, Ferrone F, Moreschini O, Fitzpatrick LA, Minisola S (2018) A challenging case of tumor-induced osteomalacia: pathophysiological and clinical implications. Calcif Tissue Int 103:465-468. https://doi.org/10.1007/s00223-018-0429-x

4. Beck L, Karaplis AC, Amizuka N, Hewson AS, Ozawa H, Tenenhouse HS (1998) Targeted inactivation of Npt2 in mice leads to severe renal phosphate wasting, hypercalciuria, and skeletal abnormalities. Proc Natl Acad Sci U S A 95:5372-5377

Publisher's note Springer Nature remains neutral with regard to jurisdictional claims in published maps and institutional affiliations.

S. Minisola

salvatore.minisola@uniromal.it

1 Department of Internal Medicine and Medical Disciplines, "Sapienza" Rome University, Viale del Policlinico 155,

00161 Rome, Italy 